\title{
Uma visão holística das práticas em saúde mental amparadas na bioética latino-americana
}

\author{
A holistic view of practices in mental health based on latin american bioethics \\ Una visión holística de las prácticas en salud mental amparadas en la bioética \\ latinoamericana
}

\section{Maria Claudia Crespo Brauner ${ }^{1}$ \\ Deise Brião Ferraz ${ }^{2}$}

\begin{abstract}
RESUMO: objetivo- Estes apontamentos têm por escopo investigar as práticas em saúde mental na perspectiva da bioética latino-americana que desponta como a visão mais adequada do contexto e das profundas diferenças do Sul em relação ao mundo, e a partir de uma visão holística. Metodologia- Realizou-se o levantamento bibliográfico pertinente a respeito da visão holística, a fim de caminhar para as ponderações a respeito das práticas em saúde mental e da necessidade de mudança de paradigma. $\mathrm{O}$ método de abordagem utilizado foi o indutivo pelo qual as particularidades encontradas nos universos observados foram utilizadas para a construção da compilação. A técnica de pesquisa foi a bibliográfica, com especial atenção às normas e literatura necessárias à elucidação das variáveis envolvidas. Resultados- Fixou-se o entendimento de que a medicina adotou o paradigma cartesiano no cuidado da saúde mental, enxergando o corpo como uma máquina e a saúde como o funcionamento perfeito dessa máquina, enquanto que o cuidado desejável em saúde mental deve ser compreendido como uma ação social inclusiva que contrarie os modelos assistenciais em saúde mental. Conclusão - Concluiu-se que uma mudança de paradigma se mostra necessária para atingir a atenção integral em cuidados com saúde mental que seja capaz de promover a dignidade humana através da humanização do tratamento e da reinserção desses pacientes em sociedade, na esteira ecológica em que se integram enquanto ser e não máquinas.
\end{abstract}

Palavras-chave: Bioética. Bioética latino-americana. Saúde Mental.

\footnotetext{
${ }^{1}$ Doutora em Direito pela Université de Rennes. Pós-Doutora na Universidade de Montreal. Professora adjunta da Faculdade de Direito da Universidade Federal do Rio Grande - FURG onde também atua como coordenadora do Mestrado em Direito e Justiça Social. É membro do Réseau Universitaire International de Bioéthique (RUIB). Pesquisadora do Conselho Nacional de Desenvolvimento Científico e Tecnológico CNPq, com Bolsa Produtividade 2. Professora convidada da Université de Toulouse - França; Université de Rennes1 - França, Université de Montreal1 - Canadá; Université Libre de Bruxelles - Bélgica; Universidade de Kyoto - Japão; Université de Lausanne - Suiça. É coordenadora do Comitê Assessor de Ciências Humanas e Sociais da FAPERGS. É líder do Diretório de Pesquisa do CNPq intitulado: Direito e Justiça Social. Email - mccbrauner@hotmail.com.

${ }_{2}^{2}$ Mestranda em Direito e Justiça Social no Programa de Pós-Graduação em Direito da Universidade Federal do Rio Grande (FURG) e bolsista CAPES. Cursou Bacharelado em Direito na FURG. Possui PósGraduação Lato Sensu em Direito do Trabalho pelo Centro Universitário Internacional (UNINTER). Também é bacharela em Comunicação Social com habilitação em Jornalismo na Universidade Católica de Pelotas (UCPEL). Advogada. Email - deisebferraz@gmail.com
} 
ABSTRACT: objective - These notes are intended to investigate mental health practices from the perspective of Latin American bioethics that emerges as the most appropriate view of the context and deep differences of the South in relation to the world, and from a holistic view. Methods: It was a pertinent bibliographical survey was carried out regarding the holistic vision, in order to move, at the last moment, to the considerations regarding mental health practices and the need for paradigm change. The method used was the inductive by which the particularities found in the observed universes were used for the construction of the compilation. The research technique used was the bibliographical one, with special attention to the norms and literature necessary to the elucidation of the variables involved. Results - Throughout the writing it was established the understanding that medicine adopted the Cartesian paradigm in mental health care, seeing the body as a machine and health as the perfect functioning of that machine, whereas the desirable care in mental health should be understood as an inclusive social action that contradicts the mental health care models. Conclusion - It was concluded that a paradigm shift is necessary to achieve comprehensive care in mental health care that is capable of promoting human dignity through the humanization of the treatment and reintegration of these patients into society, in the ecological belt in which they are integrated as being and not machines.

Keywords: Bioethics. Latin american bioethics. Mental Health.

RESUMEN: objectivo - Estos apuntes tienen por objeto investigar las prácticas en salud mental en la perspectiva de la bioética latinoamericana que despunta como la visión más adecuada del contexto y de las profundas diferencias del Sur en relación al mundo, ya partir de una visión holística. Metodología - se realizó el levantamiento bibliográfico pertinente respecto a la visión holística, a fin de caminar, en el último momento, a las ponderaciones acerca de las prácticas en salud mental y de la necesidad de cambio de paradigma. El método de abordaje utilizado fue el inductivo por el cual las particularidades encontradas en los universos observados fueron utilizadas para la construcción de la compilación. La técnica de investigación utilizada fue la bibliográfica, con especial atención a las normas y literatura necesarias para la elucidación de las variables involucradas. Resultados - A lo largo de la escritura se fijó el entendimiento de que la medicina adoptó el paradigma cartesiano en el cuidado de la salud mental, viendo el cuerpo como una máquina y la salud como el funcionamiento perfecto de esa máquina, mientras que el cuidado deseable en salud mental debe ser comprendido como una acción social inclusiva que contraríe los modelos asistenciales en salud mental. Conclusión - Se concluyó que un cambio de paradigma se muestra necesario para alcanzar la atención integral en cuidados con salud mental que sea capaz de promover la dignidad humana a través de la humanización del tratamiento y de la reinserción de esos pacientes en sociedad, en la estela ecológica en que se integran y no máquinas.

Palabras Ilave: Bioética. Bioética latinoamericana. Salud mental. 


\section{Introdução}

As linhas que seguem têm o fito de olhar as práticas em saúde mental na perspectiva da Bioética e a partir de uma visão holística. Isso porque, conforme se observa, a saúde mental está imbricada no imaginário coletivo, de forma popular, como área destinada ao tratamento da "loucura", marcada por uma cultura de institucionalização.

Quanto ao agir médico, tem-se que a medicina adotou o paradigma cartesiano no cuidado da saúde mental, enxergando o corpo como uma máquina e a saúde como o funcionamento perfeito dessa máquina, de modo que a doença é encarada como uma falha que precisa ser corrigida. Assim, a hipótese que deu origem a estes apontamentos diz respeito justamente ao fato de que as práticas em saúde mental carecem de uma visão holística.

Diante da emergência na mudança de paradigma que adote um enfoque holístico da medicina, sobretudo no que diz respeito às práticas em saúde mental, justifica-se a relevância desse estudo.

Quanto ao método de abordagem será o indutivo, pelo qual as particularidades encontradas nos universos observados serão utilizadas para a construção da pertinente compilação. A técnica de pesquisa utilizada será a bibliográfica, com especial atenção às normas e literatura necessárias à elucidação das variáveis envolvidas.

Para desvendar a pesquisa, vale apontar o caminho que se pretende percorrer: primeiramente se buscará situar a saúde mental, traçando um sucinto panorama, passando-se, no segundo momento, a abordar a bioética latino-americana. Posteriormente, será realizado o levantamento bibliográfico pertinente a respeito da visão holística, a fim de caminhar, no último momento, para as ponderações a respeito das práticas em saúde mental e da necessidade de mudança de paradigma.

\section{Bioética da Proteção}

Neste primeiro momento busca-se traçar um breve panorama do direito à saúde e dos cuidados em saúde mental. Também se faz imperioso versar a respeito da bioética latino-americana, por ser portadora de peculiaridades que a diferem da bioética norte- 
americana e que melhor atende os anseios do Sul, tudo com o condão de situar o interlocutor, conduzindo-o a uma leitura elucidativa.

\title{
1. Um breve panorama
}

As novas constituições pós Segunda Guerra Mundial carregam em si um compromisso de proteção da pessoa humana, iniciando uma nova era em relação ao seu momento anterior e preconizando por uma proteção em torno dos direitos sociais. Nesse sentido, a Constituição Federal ${ }^{3}$ de 1988 acompanhou a onda de transformações sentidas no mundo e trouxe para o seu texto um farto leque de direitos albergados.

Como não poderia ser diferente, erigiu a dignidade da pessoa humana como centro do ordenamento, irradiando essa premissa para todos os demais dispositivos. Ademais, consagrou o direito à saúde no título referente aos Direitos e Garantias Fundamentais, no artigo 6ํㅜ , com a proteção digna de uma cláusula pétrea. Criou o Sistema Único de Saúde - SUS que é o resultado da conquista de movimentos organizados, uma vez que no período que antecede à Constituição o atendimento à saúde era restrito apenas aqueles que tinham registro no emprego, com carteira assinada. Entretanto, conforme aduz Brauner e Furlan (2)

\begin{abstract}
No entanto, mesmo perante toda essa conjuntura constitucionalmente estabelecidade e garantida de proteção à saúde se observa um processo social, induzido pela atual política de mercado global, percebido como uma crescente cultura de medicalização da vida, fenômeno que induz o cidadão a uma concepção superficial de que tudo se resolve através da pílula, do fármaco, do procedimento médico e cirúrgico. (2)
\end{abstract}

O panorama que se apresenta é marcado por uma cultura do adoecimento e medicalização da vida, ao mesmo tempo em que o Estado não está pronto para promover o acesso universal e igualitário à saúde em todos os aspectos que isso envolve. Logo, a consequência imediatamente sentida é o grande volume de demandas encaminhadas ao Poder Judiciário, criando um problema social e demonstrando a

\footnotetext{
${ }^{3}$ BRASIL. Constituição (1988). Constituição da República Federativa do Brasil. Brasília, DF: Senado, 1988.
} 
debilidade das políticas públicas na área da saúde. Logo, o que se tem é um cenário não mais regido pelas necessidades humanas, mas por uma imposição do mercado.

Sobretudo no que diz respeito à Saúde Mental, o cenário é ainda mais delicado, pois, apesar da lei $10.126 / 2001^{4}$, conhecida popularmente como lei da reforma psiquiátrica, instituir um rol de direito das pessoas com transtornos mentais, como no inciso VIII e IX, exemplificativamente, tais práticas nem sempre correspondem à realidade dos cuidados com esses pacientes.

VIII - o direito a ser tratada em ambiente terapêutico pelos meios menos invasivos possíveis.

IX - o direito a ser tratada, preferencialmente, em serviços comunitários de saúde mental.

Isso porque, o Estado tem sido negligente em relação ao desenvolvimento de políticas públicas de saúde mental que superem a lógica da institucionalização, a partir da assistência e promoção de ações de saúde aos portadores de transtornos mentais, conforme prevê o artigo $3^{\circ}$ da lei supra. Contanto que a internação somente se aplique aos casos em que os recursos extra-hospitalares não são suficientes, conforme ressalta o artigo 4º da mencionada lei 10.216/2001.

Ademais disso, a visão estereotipada e sempre perpetrada no imaginário coletivo a respeito do "Iouco" que necessita de camisa de força, da pessoa acometida por depressão que é considerada fraca porque não suporta as angústias da vida, do psicopata que é perigoso como um serial killer. Muitas das vezes essas percepções estão arraigadas no imaginário social, usadas em tom de brincadeira ou mesmo de ofensa. Ou seja, em muitos outros, são exaltados apenas os quadros clínicos em detrimento do ser humano, da vida e da dignidade do portador de transtorno mental.

A respeito disso, importa refletir a respeito da dignidade da pessoa humana. Para tanto, mister se faz compreender as dimensões da dignidade da pessoa humana, a partir da complexidade que envolve tanto a pessoa humana quanto o meio no qual ela se desenvolve. Para Sarlet (13) a dignidade é inerente ao ser humano e independe de

\footnotetext{
4 BRASIL. Lei 10.216/2001. Dispõe sobre a proteção e os direitos das pessoas portadoras de transtornos mentais e redireciona modelo assistencial em saúde mental. Disponível em http://www.planalto.gov.br/ccivil_03/leis/leis_2001/l10216.htm. Acesso em 05.jul. 2017.
} 
circunstâncias concretas, sendo todos iguais em dignidade ainda que não se portem de forma igualmente digna.

O que mais importa nesse ponto é salientar que a dignidade da pessoa humana implica uma obrigação geral de respeito pela pessoa que envolve um conjunto de deveres e direitos capazes de colaborar com aquilo que Sarlet (13) chama de "florescimento humano". Em outras palavras: a dignidade deve ser vislumbrada como uma construção, de modo que a pessoa não seja considerada apenas no sentido biológico, mas também seja compreendida em seu sentido cultural, considerando que essas duas dimensões - natural e cultural se complementam e interagem mutuamente. Para Sarlet:

Assim sendo, tem-se por dignidade da pessoa humana a qualidade intrínseca e distintiva reconhecida em cada ser humano que o faz merecedor do mesmo respeito e consideração por parte do Estado e da comunidade, implicando, neste sentido, um complexo de direitos e deveres fundamentais que assegurem a pessoa tanto contra todo e qualquer ato de cunho degradante e desumano, como venham a the garantir as condições existenciais mínimas para uma vida saudável, além de propiciar e promover sua participação ativa e corresponsável nos destinos da própria existência e da vida em comunhão com os demais seres humanos. (13)

Nessa perspectiva, tem-se primordialmente que, onde não houver respeito pelo ser humano como um todo e onde não houver condições para uma existência digna, nem limitação do poder, nem o reconhecimento de direitos fundamentais, não há espaço para a dignidade da pessoa humana, independente de qual seja sua acepção. Ademais disso, na construção acerca da dignidade da pessoa humana há de se considerar todas as dimensões da dignidade e se repudiar qualquer forma de sectarismo, sobretudo no debate que envolve a bioética.

\subsection{Apontamentos bioéticos na América Latina}

Legarda (7) considera que a restauração da democracia na América Latina retomou o debate sobre o ethos médico e os sistemas de saúde e que, considerando-se a realidade que envolve o contexto da saúde - marcada por profundas diferenças, não se pode permitir um olhar que seja mero reflexo da bioética norte-americana e europeia, 
uma vez que estas não contemplam aquela por estarem inseridas em outra realidade histórica e social.

Em uma crítica ao que denomina "panfletismo terceiro mundista", Legarda (7) aduz que a presença de ideais morais em termos de princípios e valores no desenvolvimento da bioética latino-americana é compreensível, mas que isso não deve conduzir a um proselitismo demagógico que se afaste de uma análise séria e desapaixonada da bioética. Ademais, insiste em lembrar que muitos dos debates rotulados de "bioéticos", na verdade são servidos pelo sensacionalismo midiático e desconhecem os fatos científicos e problemas éticos envolvidos. Para ele:

A bioética se concebe assim, antes de tudo, como um discurso antidogmático, isto é, um discurso essencialmente crítico que se caracteriza por uma atitude dialógica que permite a pluralidade e o dissenso. A bioética a partir dessa perspectiva desenvolveria uma metanarrativa que poderia "horizontalizar" os argumentos e, portanto, desvelar a arquitetura axiológica daqueles que participam do diálogo. (7)

Desse modo, a bioética assume um papel mediador que incentiva um diálogo entre saberes e disciplinas e propõe que o debate bioético contribua ao processo de deliberação sobre uma determinada questão e em determinada sociedade, a partir de uma teoria particular, levando-se em consideração a comparação entre outros contextos culturais equivalentes. Outro ponto a ser discutido diz respeito ao estatuto epistemológico da bioética e o fato de nunca ter se resolvido o que pode ser considerado pertinente e pertencente à bioética e o que não poderia, quais seus limites e suas possibilidades? O que se poderia concluir é que esse processo ainda se mostra inacabado diante da ordem do tempo que é ainda muito recente e se encontra em uma escalada evolutiva.

Talvez esteja, entre as mais importantes contribuições de Legarda (7) a ousadia ao descrever três traços característicos da bioética latino-americana consubstanciados em seu caráter teórico vinculado às humanidades, seu caráter inclusivo que abrange um amplo grupo de problemas e temas e, por fim, o caráter de movimento social acompanhado de ativismo que permeia desde a visão feminista dos direitos da mulher até as minorias étnicas, o que é muito peculiar e enquadra perfeitamente a América 
Latina a partir de uma visão decolonial e insurgente de explosão de movimentos sociais após um recente e nebuloso período de ditadura.

Por fim, é indispensável que se pense na bioética como uma ferramenta mediadora entre disciplinas, que permite e promove seu diálogo e, por isso, não pode ser reduzida a uma mera aplicação de princípios abstratos em situações concretas. Embora seja clara a tensão existente entre a vertente liberal de aposta pelos direitos individuais que é muito cara ao ethos médico norte-americano, como na bioética de Engelhardt (9) na qual se sobressai o princípio da autonomia pessoal "Faça aos outros o bem deles." (9) versus os direitos econômicos e sociais que fazem parte das preocupações latinoamericanas.

Ressalta-se que, nessa quadra da história, não cabe mais a polarização no debate que se impunha outrora à respeito da autonomia versus paternalismo na bioética. $\mathrm{O}$ que se tem na atualidade é uma preponderância clara do respeito à autonomia do paciente, fundada na consideração da sua capacidade de julgamento e escolha, em detrimento do paternalismo profissional, de modo que o mais oportuno é que, desde que haja aptidão, o paciente deve participar da escolha das práticas terapêuticas conjuntamente com clínico que the assiste, adotando o consentimento informado. Pode-se entender por autonomia como sendo:

Uma decisão racional, expresse ou não a preferência, a autonomia é uma decisão que exprime a preferência, seja ou não racional. $A$ este princípio fica associado o consentimento informado no contexto da consulta profissional. Entretanto, além da liberdade de optar, a ação autônoma também pressupõe a liberdade de ação, requer que a pessoa seja capaz de agir conforme as suas escolhas feitas e as decisões tomadas. Desta forma, a pessoa autônoma é aquela que tem liberdade de pensamento, livre de coações internas ou externas, para escolher entre as opções que lhe são apresentadas. (7)

Uma vez que a autonomia do paciente emergiu no tratamento médico em termos valorativos, levantou a discussão a respeito da vulnerabilidade. Logo exsurge a reflexão em torno de pacientes que representam risco à própria integridade e a de terceiros e, de pronto, nota-se que o modelo autonomista de bioética, principalmente preconizado por Engelhardt, não deve ser aplicado às cegas. Eis que surge o espaço de aplicação da Bioética da Proteção: 
Como visto, a Bioética da Proteção se aplica pertinentemente a qualquer paciente moral que não possa se defender sozinho ou agir autonomamente por alguma razão independente de sua vontade e suas capacidades. Esta é a definição estrita dessa proposta, enunciada, inicialmente, para enfrentar os conflitos morais que surgem em saúde pública nos países em desenvolvimento. (14)

Nesse ponto que se erige a necessidade de falar em vulnerabilidade. $\mathrm{Na}$ acepção de Felício e Pessini (10), existem três sentidos para a vulnerabilidade no âmbito da bioética, quais sejam a vulnerabilidade como condição humana universal, a vulnerabilidade como característica particular de pessoas e grupos e a vulnerabilidade como princípio ético internacional.

A vulnerabilidade como condição humana universal pressupõe que o ser humano assume essa condição como todo ser vivo, não somente em relação ao seu organismo, mas também quanto ao seu projeto existencial. A vulnerabilidade como característica particular de pessoas e grupos diz respeito à compreensão do ser humano como vulnerável e, a partir disso, da obrigatoriedade de sua defesa e proteção. Inclusive, a Declaração de Helsinque sobre Princípios Éticos para Pesquisa Médica Envolvendo Seres Humanos, redigida pela Associação Médica Mundial (WMA), destina um tópico específico voltado para a pesquisa em grupos e indivíduos vulneráveis. Se extrai da leitura dessas diretrizes que esse tipo de pesquisa só se justifica se o referido grupo se beneficiar dos resultados e, desde que o médico obtenha o consentimento informado do representante legal do paciente incapaz, se for o caso.

Por fim, a vulnerabilidade como princípio ético internacional constitui preocupação de documentos internacionais como a Declaração Universal sobre Bioética e Direitos Humanos da Unesco ${ }^{5}$, que traz em seu artigo $8^{\circ}$ a necessidade de consideração da vulnerabilidade humana para fins de proteção da integridade pessoal dos indivíduos.

\section{Acerca do pensamento ecológico}

A visão holística pode ser entendida como produto do novo paradigma holístico. $O$ referido paradigma é apontado por Crema (8) como "[...] uma resposta à crise global da consciência humana [...] o substrato de uma verdadeira mutação de consciência que

\footnotetext{
5 UNESCO. Declaração Universal sobre Bioética e Direitos Humanos. Disponível em http://unesdoc.unesco.org/images/0014/001461/146180por.pdf. Acesso em 05 jul. 2017.
} 
transcorre, atualmente, nas mais diversas localidades do globo terrestre.". Trata-se, ainda, de uma nova racionalidade que supera a epistemologia cartesiana tida até então como indiscutível.

O surgimento de um novo paradigma se deu diante do fracasso do modelo mecanicista e disciplinar em fornecer respostas satisfatórias à crise vivenciada. Isso graças a seu enfoque disciplinar que caminhou rumo a uma fragmentação do conhecimento, exigindo a nova abordagem transdisciplinar, fundada sob a cosmovisão.

Para falar em paradigma, Crema (8) discorre que a noção de paradigma representa em um sentido sociológico todo o sistema de crenças, procedimento, técnicas, que amparam a comunidade científica em uma determinada época. Em um sentido mais profundo, paradigma faz parte desse todo. Mas de uma forma geral, pode ser compreendido como um modelo compartilhado e aceito por seus pares para compreender a realidade.

Assim, apesar das certezas trazidas por um paradigma em sua época de vigência, o que leva a sua mudança é justamente a constatação de que houve uma falha sensivelmente observada e que clama por uma renovação. Para responder a esse momento de crise, somente o surgimento de um novo paradigma. Ele deve promover uma ruptura e ser acompanhado da resistência dos signatários do velho modelo, como é de se esperar. Entretanto, o paradigma só virá a ser invalidado caso outro torne-se disponível e satisfatório.

Crema (8) identifica a avassaladora crise vivenciada na atualidade, considerando que até mesmo a espécie humana corre risco iminente de destruição, crise melhor visualizada nas palavras do autor:

Tal crise planetária, multidimensional em sua abrangência, pode ser traduzida como uma crise de fragmentação, atomização e desvinculação. Como nunca antes o homem encontra-se esfacelado no seu conhecimento, atomizado no seu coração, dividido no seu pensar e sentir, compartimentalizado no seu viver. Refletindo uma cultura racional e tecnológica encontramo-nos fragmentados e encerrados em compartimentos estanque. Interiormente divididos, em permanente estado de conflito, vivemos num mundo também fracionado em territórios e nacionalidades, em estado de guerra infindável. (8). 
A atual crise foi conduzida sob os auspícios de um falacioso progresso tecnológico, que acompanharia a ideia de desenvolvimento. Ledo engano. Hoje é possível perceber que pode perfeitamente haver uma contraposição marcante entre quantidade de bens e qualidade de vida, o que comprova a tese exposta por Morin (12) de que a palavra progresso não se recobre de obviedade.

Nesse sentido, importa lembrar que Morin (12) aponta que é preciso esclarecer quais denominações são utilizadas para identificar as noções de progresso e de conhecimento e, para tanto, propõe uma reflexão sobre a ideia de progresso. Aduz que o progresso é aparentemente sustentado pela tradução simultânea quantitativa e qualitativa. Entretanto essa definição não é indubitável visto que, conforme depreendese da realidade vivenciada, nem sempre as características qualitativas acompanham as quantitativas, abrindo brecha para o questionamento a respeito.

Outra ideia ventilada por Morin (12) a respeito do progresso é de que somente se concebe o progresso associado à ideia de racionalidade e organização, o que deve ser superado, devendo haver um "[...] progresso na idéia de progresso, que deve deixar de ser noção linear, simples, segura e irreversível para tornar-se complexa e problemática.". (12). Não obstante, Morin aponta outros problemas como a falta de comunicação entre os conhecimentos especializados, provocando a regressão geral do conhecimento. Essa realidade conduz a uma escolha entre ideias especializadas e operacionais que não correspondem à realidade. Conforme aduz:

Além disso, a hiperespecialização dos saberes disciplinares reduziu a migalhas o saber científico (que só pode ser unificado em níveis de elevada e abstrata formalização), sobretudo nas ciências antropossociais, que têm todos os vícios da sobreespecialização sem ter suas vantagens. Assim, todos os conceitos molares que abrangem várias disciplinas e não são reconstituídos pelas tentativas interdisciplinares. Torna-se impossível pensar cientificamente o indivíduo, o homem, a sociedade. (12)

Ainda, nesta mesma linha, importa lembrar que estamos na época da "big science", dotada de grandes poderes e, em contrapartida, os cientistas não detêm mais o poder que emana do seu conhecimento porque esse poder está concentrado nas mãos dos dirigentes das empresas e autoridade do Estado. O risco, contudo, consiste na criação 
de um saber anônimo que não corresponde ao saber conforme concebido na história. Esse novo saber científico nasce para ser usado da forma que melhor aprouver às potências, comprovando que nesses novos tempos, tanto os cidadãos quanto os cientistas estão sendo desapossados do conhecimento.

Seguindo a mesma linha de pensamento, Capra (4) aborda a nova compreensão científica em todos os níveis dos sistemas vivos. Baseia-se na crise atual percebida em todas as esferas da sociedade, e tratada de forma isolada e disciplinar, quando na verdade são problemas sistêmicos que demandam respostas integradoras. Exemplificativamente, o autor situa esse concatenamento sistêmico e interdependente:

Por exemplo, somente será possível estabilizar a população quando a pobreza for reduzida em âmbito mundial. A extinção de espécies animais e vegetais numa escala massiva continuará enquanto o Hemisfério Meridional estiver sob o fardo de enormes dívidas. A escassez dos recursos e a degradação do meio ambiente combinam-se com populações em rápida expansão, o que leva ao colapso das comunidades locais e à violência étnica e tribal que se tornou a característica mais importante da era pós-guerra fria. Em última análise, esses problemas precisam ser vistos, exatamente, como diferentes facetas de uma única crise, que é, em grande medida, uma crise de percepção. Ela deriva do fato de que a maioria de nós, e em especial nossas grandes instituições sociais, concordam com os conceitos de uma visão de mundo obsoleta, uma percepção da realidade inadequada para lidarmos com nosso mundo superpovoado e globalmente interligado. (4)

Logo, exsurge a necessidade de uma ruptura paradigmática que contrarie 0 paradigma mecanicista do século XVII - melhor desenvolvido por Newton e Descartes, adotando a visão holística ou ecológica. Sendo que esta última nomenclatura já demonstrou melhor atender a proposta integradora, porque carrega consigo a ideia de conexão com o meio ambiente a partir de um pensar ecológico e não antropocêntrico, voltado para a Terra e não para o ser humano. Em outras palavras, funda-se um sistema ético novo que acolhe os seres humanos em uma relação de partícipes do meio ambiente em que "[...] a natureza viva está alicerçada na experiência profunda, ecológica ou espiritual, de que a natureza e o eu são um só.”. (4). 
Essa experiência ecológica introduz o ser humano como parte da teia da vida, inspirando-o no cuidado da natureza baseado no pertencimento. O fracasso do paradigma mecanicista é visualizado em sua ótica estanque baseada na competitividade e no progresso material ilimitado e praticante da dominação exploradora e antiecológica.

\section{Ponderações na prática de Saúde Mental: a necessidade de mudança de paradigma}

O paradigma cartesiano-newtoniano difundido desde o século XVII, não se mostra satisfatório para apresentar respostas à crise atualmente vivenciada, conforme já esclarecido. As ciências foram de toda sorte influenciadas por essa visão cartesiana e a necessidade de mudança paradigmática se ergue justamente para pensar respostas.

Nota-se que a medicina moderna adotou substancialmente a visão cartesiana que trata o paciente como máquina, abdicando de seu todo, sendo que esse tratamento dispensado não é mais desejável em termos de saúde no seu sentido mais amplo e, portanto, clama por um outro enfoque, aqui proposto como o enfoque holístico. Nesse aspecto:

O corpo humano é considerado uma máquina que pode ser analisada em termos de suas peças; a doença é vista como um mau funcionamento dos mecanismos biológicos, que são estudados do ponto de vista da biologia celular e molecular; o papel dos médicos é intervir, física ou quimicamente, para consertar o defeito no funcionamento de um específico mecanismo enguiçado. (5)

A medicina moderna, ao adotar o paradigma cartesiano como modelo, reduziu o corpo a uma máquina e a doença como uma falha no funcionamento desta, deixando de olhar para o processo de cura. Capra (5) aduz que o termo "curar" é visto com alguma desconfiança porque extrapola os tímidos limites do reducionismo que se impõe. Sobretudo porque a cura envolve uma teia complexa que estabelece interação entre aspectos físicos, psicológicos, sociais e o, todo representando uma resposta do organismo às influências causadoras de tensão.

Não obstante, a partir da visão cartesiana a medicina tem entendido a saúde como a ausência de doença. Essa visão é absolutamente restrita. A visão holística a respeito 
de saúde contempla a saúde do indivíduo, mas também a saúde da sociedade, as patologias sociais. Para a concepção holística:

[...] a enfermidade física é apenas uma das numerosas manifestações de um desequilíbrio básico do organismo. Outras manifestações podem assumir a forma de patologias psicológicas e sociais; e quando os sintomas de uma enfermidade física são efetivamente suprimidos por intervenção médica, uma doença pode muito bem expressar-se de algum outro modo. (5)

Ademais, no que concerne especificamente ao tratamento de doenças mentais manifesta-se uma preferência pela medicação, que não promove a cura, mas sim o controle. Ocorre que, o cuidado envolve também questões pessoais, emocionais e sociais e se esbarra em diversas dificuldades, sobretudo no contexto do SUS. Mas medidas devem ser tomadas nesse sentido, uma vez que o cuidado em saúde mental requer diversificadas técnicas associadas que "[...]visam potencializar as habilidades desta população, melhorar a interação do doente mental a sua rede social, garantir seus direitos como cidadão e sua adequação também aos deveres que esta condição exige.”. (6)

Assim, desde o diagnóstico, o cuidar em saúde mental pode ser compreendido como uma ação social, desde uma concepção inclusiva que está de acordo com as mudanças nos modelos assistenciais em saúde mental. De tratamentos exclusivamente curativos e asilares, passou a ser desejável uma atenção preventiva e interdisciplinar, focada na integralidade do sujeito e na dignidade da pessoa humana, que só será possível diante da mudança de paradigma que abandone a visão cartesiana do corpo, do sujeito e da doença e olhe para o ser humano como um todo integrado com o meio ambiente, sofrendo e causando influências.

Nessa trilha, a Reforma Psiquiátrica (ou Movimento Antimanicomial), contemplada na Lei no 10.216/2001 surge como um movimento sociopolítico na seara da saúde pública, cujo documento de expressividade é referido à Declaração de Caracas, aprovada na Conferência Regional para a Reestruturação da Atenção Psiquiátrica na América Latina dentro dos Sistemas Locais de Saúde, convocada pela Organização Mundial da Saúde, que contou com a aderência brasileira. Por meio de uma complexa e sistemática rede de políticas públicas, a Reforma Psiquiátrica brasileira modifica o 
atendimento à população com deficiência psicológica, redirecionando o modelo de assistência psiquiátrica, prevendo cuidado especial aos pacientes, impulsionando a desinstitucionalização de pessoas do hospital psiquiátrico. (3)

Embora as dificuldades da implementação efetiva do novo modelo de tratamento dos pacientes com transtornos mentais, o atual paradigma é compatível com a dignidade da pessoa humana e preconiza a expectativa em favor da cidadania. $O$ desafio a ser enfrentado consiste em assegurar a humanização do tratamento e proporcionar a reinserção desses pacientes em sociedade. (3)

\section{Conclusão}

Conforme abordado, as práticas em Saúde Mental trazem consigo celeumas como as aqui apresentadas, que giram em torno de questões como a autonomia dos pacientes e sua vulnerabilidade. Isso porque hoje, a partir de uma visão bioética, se mostra ético e desejável incluir o paciente no tratamento, a partir de um consentimento informado, desde que ele seja capaz de fazer escolhas, abdicando-se do paternalismo anteriormente existente. Sob esse viés, os impasses bioéticos exigem uma análise cuidadosa que considere todos esses elementos envolvidos nos processos de decisão. Até mesmo porque onde não houver respeito pelo ser humano como um todo e onde não houver condições para uma existência digna, nem o reconhecimento de direitos fundamentais, não há espaço para a dignidade da pessoa humana.

$\mathrm{Na}$ área clínica, conforme abordado, carrega-se o estigma da "loucura" (como se a psiquiatria só servisse para "loucos") e do tratamento dos transtornos mentais a partir de um enfoque na institucionalização. Entretanto, os hospitais psiquiátricos deixaram de constituir a base do sistema assistencial, inclusive após a promulgação da lei da reforma psiquiátrica que instituiu um rol de direitos do paciente e prima pela investida na rede de serviços extra-hospitalares, a partir de um modelo de atenção integral à saúde que busca a reinserção social.

A medicina moderna, ao adotar o paradigma cartesiano como modelo, reduziu o corpo a uma máquina. A visão da saúde ultrapassa a noção de ausência de doença, o que requer que se considere o aspecto psicológico da saúde. Entretanto, o cuidar em saúde mental que se quer deve ser compreendido como uma ação social, desde uma 
concepção inclusiva que está de acordo com as mudanças nos modelos assistenciais em saúde mental, focada na integralidade do sujeito e na dignidade da pessoa humana. Tal enfoque só será possível diante da mudança de paradigma que abandone a visão cartesiana do corpo, do sujeito e da doença e olhe para o ser humano como um todo integrado com o meio ambiente, sofrendo e causando influências. Essa experiência ecológica é a única capaz de introduzir o ser humano como parte da teia da vida.

\section{Referências}

1.Associação Médica Mundial. Declaração de Helsinque da Associação Médica Mundial: princípios éticos para pesquisa envolvendo seres humanos. Jorge MR, tradutor. Disponível emhttps://www.amb.org.br/_arquivos/_downloads/491535001395167888_DoHBrazilianP ortugueseVersionRev.pdf. [ Acesso em 05.jul.2017].

2.Brauner MCC, Furlan KM. O crescente processo de medicalização da vida: entre a judicialização da saúde e um novo modelo biomédico. In: Brauner MCC. Pierre O, organizador. Direitos Humanos, Saúde e Medicina: uma perspectiva internacional. Rio Grande: Ed. Furg, 2013. p. 103-132.

3.Brauner MCC, Junior C, Gularte LR. Direito fundamental à saúde psicológica: vulnerabilidade, consentimento e cidadania sob o prisma jurídico-bioético. In: Revista da AJURIS - Porto Alegre, 44 (142): 227-243, 2017.

4.Capra F. A teia da vida: uma nova compreensão científica dos sistemas vivos. Eichemberg NR, tradutor. São Paulo: Editora Cultrix, 1997.

5.Capra F. O ponto de mutação. 26. ed. São Paulo: Cultrix, 2006.

6.Cardoso L, Galera SAF. O cuidado em saúde mental na atualidade. In: Revista da Escola de Enfermagem da USP, 2011.45 (3): 687-691.

7.Costa JRE, Anjos MF, Zaher VL. Para compreender a doença mental numa perspectiva de bioética. In Revista Bioethikos, 2007.1 (2): 103-110.

8.Crema, R. Introdução à visão holística: breve relato de viagem do velho ao novo paradigma. São Paulo: Summus, 1989.

9.Engelhadt JR, Tristram H. Os princípios da Bioética. In Fundamentos da

Bioética. 4aㅡ Ed. São Paulo: Loyola, 2011. p. 131-168. 
10.Felicio JL, Pessini L. Bioética da Proteção: vulnerabilidade e autonomia dos pacientes com transtornos mentais. In: Revista Bioética, 2009. p. 203-220.

11.Legarda GC. Uma leitura crítica da bioética latino-americana. In: Bioética na lberoAmérica: história e perspectivas. São Paulo: Loyola, p. 329-367, 2007.

12.Morin E. A ideia de progresso do conhecimento. In: Ciência com consciência. Tradução de Maria D. Alexandre e Maria Alice Sampaio Dória. Rio de Janeiro: Bertrand Brasil, 2000.

13.Sarlet IW. As dimensões da dignidade da pessoa humana: uma compreensão jurídico-constitucional aberta e compatível com os desafios da biotecnologia. In: Sarlet IW, Leite G, organizadores. Direitos Fundamentais e biotecnologia. São Paulo: Método, 2008. p. $13-43$

14.Schramm FR. Bioética da Proteção: ferramenta válida para enfrentar problemas morais na era da globalização. In: Revista Bioética, 2008. 16 (1): 11-23.

\section{Como citar este artigo:}

Brauner MCC, Ferraz DB. Uma visão holística das práticas em saúde mental amparadas na bioética latino-americana. Revista Cadernos Ibero-Americanos de Direito Sanitário. 2017 out./dez, 6(4):10-26. 